\title{
Microbiology Specimen Subcategory
}

National Cancer Institute

\section{Source}

National Cancer Institute. Microbiology Specimen Subcategory. NCI Thesaurus. Code C87919.

A subdivision of microbiology specimen data. 